\title{
Recovery of cobalt from lithium-ion batteries using fluidised cathode molten salt electrolysis
}

\author{
Mateen Mirza, Rema Abdulaziz*, William C. Maskell, Chun Tan, Paul R. Shearing, \\ Dan J.L. Brett*
}

Electrochemical Innovation Lab, Department of Chemical Engineering, University College London, Torrington Place, London WC1E 7JE, United Kingdom

\section{A R T I C L E I N F O}

\section{Article history:}

Received 6 April 2021

Revised 11 May 2021

Accepted 24 June 2021

Available online 8 July 2021

\section{Keywords:}

Battery recycling

Molten salts

Fluidised cathode

Li-ion batteries

$\mathrm{LiCoO}_{2}$

\begin{abstract}
A B S T R A C T
The future need to recycle enormous quantities of Li-ion batteries is a consequence of the rapid rise in electric vehicles required to decarbonise the transport sector. Cobalt is a critical element in many Li-ion battery cathode chemistries. Herein, an electrochemical reduction and recovery process of $\mathrm{Co}_{\text {from }} \mathrm{LiCoO}_{2}$ is demonstrated that uses a molten salt fluidised cathode technique. For the Li-Co-O-Cl system, specific to the experimental process, a predominance diagram was developed to aid in understanding the reduction pathway. The voltammograms indicate two 2-electron transfer reactions and the reduction of $\mathrm{CoO}$ to $\mathrm{Co}$ at $-2.4 \mathrm{~V}$ vs. $\mathrm{Ag} / \mathrm{Ag}^{+}$. Chronoamperometry revealed a Faradaic current efficiency estimated between $70-$ $80 \%$ for the commercially-obtained $\mathrm{LiCoO}_{2}$ and upwards of $80 \%$ for the spent Li-ion battery. The molten salt electrochemical process route for the recycling of spent $\mathrm{Li}$-ion batteries could prove to be a simple, green and high-throughput route for the efficient recovery of critical materials.
\end{abstract}

(C) 2021 The Authors. Published by Elsevier Ltd.

This is an open access article under the CC BY license (http://creativecommons.org/licenses/by/4.0/)

\section{Introduction}

Lithium-ion batteries (LiBs) have found varied use in portable energy storage devices [1,2], power tools and electric vehicles, and have the potential for larger-scale stationary electric storage [3]. Compared with alternative battery chemistries, they possess high energy and power densities, long cycle lifespans and flexible operating conditions [4,5]. The use of LiBs is set to increase substantially with the electric vehicle revolution, driven by the need to decarbonise the transportation sector to meet global targets of reduced greenhouse gas emissions [6]. Although the growth of the energy storage market is a positive development for society, it brings with it a number of challenges; such as, the scarcity of raw materials like cobalt [7-9], and the environmental footprint of production, towards which the extraction of these materials is a large contributor $[10,11]$. The recycling of LiBs, and the recovery of valuable materials, would provide a solution to this, and is an essential part of the future life cycle of energy storage devices.

There are currently five main recycling methods: pyrometallurgical recovery, physical materials separation, hydrometallurgical metals reclamation, direct recycling and biological metals recla-

\footnotetext{
* Corresponding authors. Brett).
}

mation [12]. Current commercially available processes are summarised by Velázquez-Martínez et al. [13]. In these processes the key step is to break the chemical bonds of the cathode material, in the case of $\mathrm{LiCoO}_{2}$, so that the $\mathrm{Li}$ and $\mathrm{Co}$ can be converted to two separate species that can be recovered by precipitation [14], phase separation [15] or solvent extraction [16,17].

Molten salts, when compared to slags and aqueous solutions, make excellent electrolytes, due to their large potential windows and high ionic conductivity. They have been used for refining and extracting metals and alloys [18-25], materials synthesis [2628] and energy storage [29-32]. Recently, Qu et al. [33] used a low-temperature molten salt roasting approach to obtain $\mathrm{Li}$ and regenerate $\mathrm{LiCoO}_{2}$; and Zhang et al. [34] showed that a molten salt electrochemical process can be used to recover $\mathrm{Co}$ and $\mathrm{Li}$ from spent $\mathrm{LiCoO}_{2}$-based batteries. Using this method, one is able to directly manipulate the reduction process by applying controlled electrode potentials, instead of using reducing agents, as traditionally done. The potential flowsheet of this electrochemical process is outlined in Fig. 1. The salt used was a $\mathrm{Na}_{2} \mathrm{CO}_{3}-\mathrm{K}_{2} \mathrm{CO}_{3}$ eutectic, and they managed to recover cobalt, and cobalt oxide, that was used to regenerate $\mathrm{LiCoO}_{2}$ by heat treating with the $\mathrm{Li}_{2} \mathrm{CO}_{3}$ product formed by leaching out the salt. The precursor for the electrochemical reaction was a solid pellet of cathode material. Furthermore, the recycling of $\mathrm{LiCoO}_{2}$ has also been reported to occur by electrolytic and ultrasonic enhanced leaching [35,36], use of grape seed and glucose as chemical reductants $[37,38]$ as well 


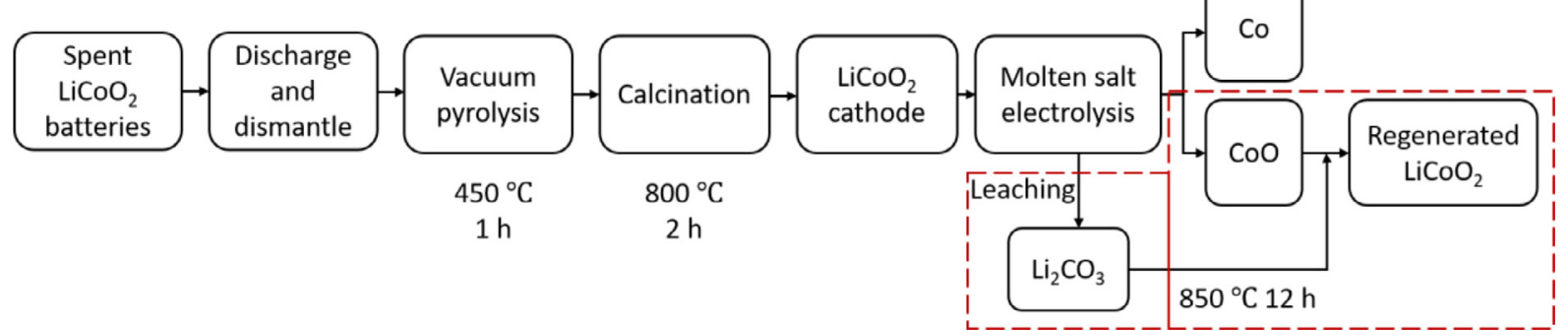

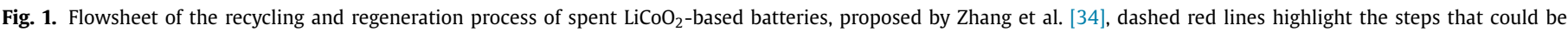
forgone following the process described in this work.

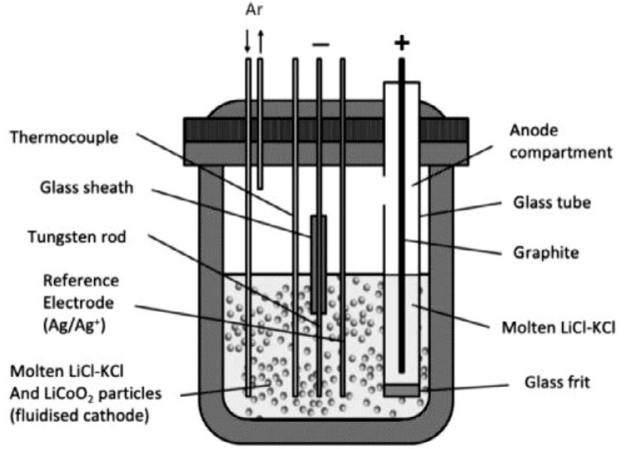

(a)

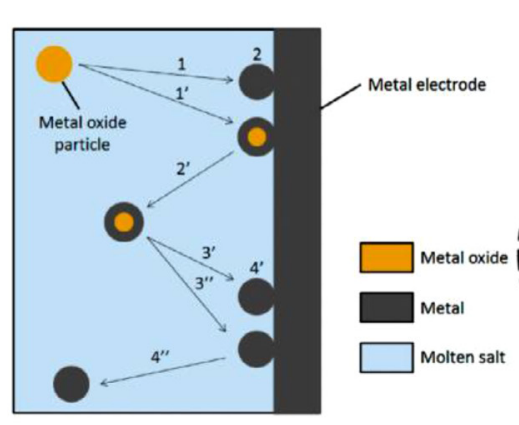

(b)

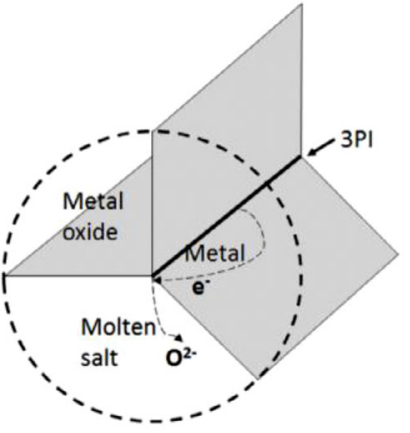

(c)

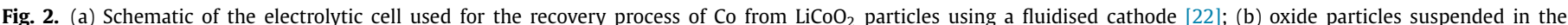

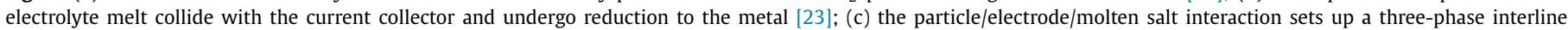
(3PI) with minimal $\mathrm{O}^{2-}$ ion build-up adapted from Deng et al. [45].

as a range of other studies which explore electrochemical methods and process optimisation and kinetics for leaching of metals and cobalt [39-42].

This manuscript describes how cobalt-containing particles $[43,44]$ can be suspended in a molten salt fluidised cathode process [24] to produce cobalt metal from commercially-obtained and spent $\mathrm{LiCoO}_{2}$ from $\mathrm{LiB}$ cells. $\mathrm{LiCl}-\mathrm{KCl}$ eutectic has been selected as a suitable electrolyte, with high Faradaic efficiency, whilst eliminating the leaching and regeneration steps (Fig. 1), with associated cost reductions. The decision to forgo the regeneration step was made based on the fact that the market share of $\mathrm{LiCoO}_{2}$ cathode material is declining [12]; thus, producing high-quality Co metal for other uses and to make other types of cathode materials (e.g. NMC) is considered to be advantageous. The fluidised cathode, which was previously developed by the authors for the production of tungsten, and for nuclear reprocessing applications, which include the formation of uranium [22-24], is a robust and dynamic system, in which kinetics are enhanced by the agitation of particles in the electrolyte melt. A schematic of the process is presented in Fig. 2 (a), (b) illustrates the pathway for metal oxide particle reduction; (c) describes the three-phase interline (3PI) of metal, metal oxide, and salt necessary for reduction reactions to take place.

\section{Experimental}

\subsection{The electrochemical cell}

A tall-form beaker made from borosilicate glass $(250 \mathrm{ml}$, Duran, SLS) was used as a primary container for both the molten salt system and metal oxide, in this case $\mathrm{LiCoO}_{2}$, throughout the experiment. This beaker was secured within a borosilicate flanged glass beaker (internal diameter $70 \mathrm{~mm}$, outer diameter $120 \mathrm{~mm}$, height $300 \mathrm{~mm}$, GPE Scientific Limited). It was found that borosilicate glass proved a suitable material not only in withstanding these intermediate temperatures $\left(\sim 450{ }^{\circ} \mathrm{C}\right)$ but also in avoiding unwanted chemical interactions with the metal and metal oxide. The cell was heated using a Vecstar programmable furnace and was raised to $450{ }^{\circ} \mathrm{C}$ at a linear ramp rate of $100{ }^{\circ} \mathrm{C} \mathrm{h}^{-1}$. An inert high purity argon gas (99.998\%, BOC) flowed through a ceramic tube (internal diameter $5 \mathrm{~mm}$, Multi-lab, Quartz and Ceramic Technology) at a constant rate. The assembly of the cell was carried out inside an inert argon gas glovebox. The molten salts in this study comprised of $150 \mathrm{~g}$ anhydrous lithium chloride (Extra Pure, SLR, Fisher Scientific) and potassium chloride (Certified AR for Analysis, Fisher Scientific) in the ratio of $59-41 \mathrm{~mol} \%$, respectively. Both salts were dried under vacuum at $150{ }^{\circ} \mathrm{C}$ for $24 \mathrm{~h}$ prior to use to ensure all residual moisture from the salts was adequately removed.

\subsection{Electrodes and cathode materials}

For the fluidised cathode setup, a tungsten rod (99.95\% metals basis, $1.5 \mathrm{~mm}$ diameter, Alfa Aesar) was used with a glass sheath that had been fused around the shaft of the rod prior to experimental studies. The rod was modified because of the fluctuating height of the melt due to agitation. The working electrode was compared to an $\mathrm{Ag} / \mathrm{AgCl}$ reference electrode which is known for its stable and well-defined potential [46]. Specifically, a silver wire (0.203 mm diameter, 99.95\% metals basis, Alfa Aesar) was placed inside a glass tube with $1 \mathrm{wt} \% \mathrm{AgCl}$ (99.999\% trace metals basis, Sigma Aldrich) in $1 \mathrm{~g} \mathrm{LiCl}-\mathrm{KCl}$ (59-41 mol.\%). The auxiliary electrode, a high-density graphite rod (99.9995\% metal basis, $3.05 \mathrm{~mm}$ diameter, Alfa Aesar), was inserted into a glass fritted (porosity 5) anode compartment with $10 \mathrm{~g} \mathrm{LiCl}-\mathrm{KCl}$ which contained a small aperture to allow any anodic gases $\left(\mathrm{CO}_{2}\right.$ from the oxide ion reaction with the graphite anode) produced to escape and to prevent the re-oxidation of any reduced cobalt particles. It should be 
noted that containment of the counter electrode behind a glass sheath and frit will add to the IR drop in the cell. However, this was not seen to affect the efficacy of the approach at this scale, for this high conductivity salt and the compliance of the potentiostat used. For scale-up to a practical system, further cell engineering will be required that includes optimisation of the working and counter electrode shape and placement, compartment separation and electrolyte agitation mechanism. An identical setup was used to conduct the 'static' experiments (quiescent electrolyte). In this setup, the $\mathrm{LiCOO}_{2}$ particles were allowed to settle at the bottom of the crucible, the working and reference electrodes were immersed through them.

Spent commercial LiBs (Polymer Li-ion cell, $3.7 \mathrm{~V}, 400 \mathrm{~mA} \mathrm{~h}$, AA Portable Power Corp) were also used in the trials to determine the efficiency of recovering Co from spent LiBs compared with commercially-obtained pure-phase $\mathrm{LiCoO}_{2}$ (97\%, Alfa Aesar). Initially, the Li-ion pouch cell was discharged using a battery cycler (BioLogic, BCS-805) to the manufacturer's safe discharge-limit $(2.75 \mathrm{~V})$. The pouch cell was then dismantled inside a glovebox $\left(<0.5 \mathrm{ppm} \mathrm{O}_{2} / \mathrm{H}_{2} \mathrm{O}\right.$ ), where the cathode layer was separated from the anode and washed in dimethyl carbonate solution (DMC) for the initial removal of electrolyte. After this, the obtained cathode scrap was heated using a modular horizontal tube furnace (Carbolite) at $450{ }^{\circ} \mathrm{C}$ for $1 \mathrm{~h}$ under an inert argon atmosphere to remove the polyvinylidene fluoride (PVDF) binder. The cathode powder was then calcined at $800{ }^{\circ} \mathrm{C}$ in air for a further hour to burn off acetylene black and any residual organic additives. An agate mortar and pestle was used to manually grind the thermally-treated $\mathrm{LiCoO}_{2}$ to a fine powder for further processing.

\subsection{Procedure}

Electroanalytical studies, including cyclic voltammetry and chronoamperometry, were undertaken using a computer-controlled potentiostat (Reference 3000, Gamry instruments). The electrochemical procedure was carried out with a constant flow of argon gas, resulting in a homogeneous distribution of electrolyte and metal oxide particles. The product materials were characterised using a scanning electron microscope (Zeiss EVO MA10, accelerating voltage: $15.0 \mathrm{kV}$ ) and energy dispersive X-ray spectroscopy (Oxford Instruments, INCAx-act, PentaFET Precision). A three-electrode electrolysis setup was employed to perform electrochemical experiments and only absolute currents are reported to account for varying electrode surface area. The current collector was immersed $\sim 4 \mathrm{~cm}\left(1.90 \mathrm{~cm}^{2}\right)$ within the melt during both the fluidised and static measurements. An identical process was used for the recovery of commercially-available $\mathrm{LiCoO}_{2}$ powder and spent Li-ion pouch cell, any differences between the studies are made clear in the manuscript.

\section{Results and discussion}

\subsection{Thermodynamic analysis}

To help understand the reduction pathway of $\mathrm{LiCoO}_{2}$ in a $\mathrm{LiCl}-$ $\mathrm{KCl}$ eutectic system a predominance diagram [47-50] was generated for the Li-Co-O-Cl system. Predominance diagrams are analogous to Pourbaix diagrams; however, the former compare the standard electrode potential to the negative logarithm of $\mathrm{O}^{2-}$ ion activity, $\mathrm{pO}^{2-}$ rather than $\mathrm{pH}$. All thermodynamic data used in producing the diagram has been obtained from HSC Chemistry 6.0 database. The diagram in Fig. 3 indicates the stability for different cobalt oxides (II/III) and cobalt metal at $500{ }^{\circ} \mathrm{C}$. From the thermodynamic analysis, one can assume that the lithium in $\mathrm{LiCoO}_{2}$ ionises with the rest of the ions in the $\mathrm{LiCl}-\mathrm{KCl}$ melt, as per Eq.

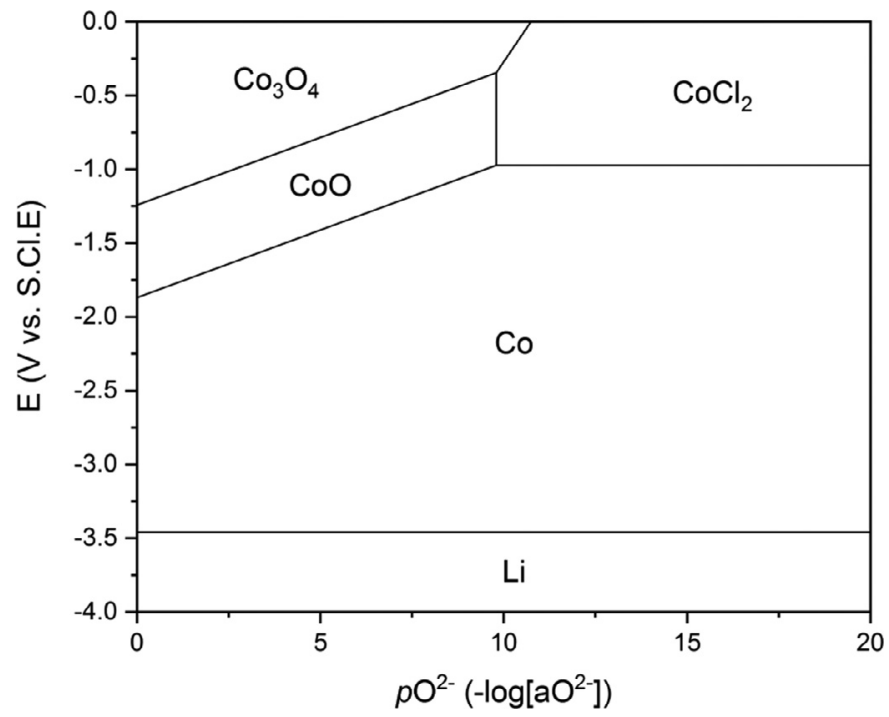

Fig. 3. Predominance diagram of the $\mathrm{Li}-\mathrm{Co}-\mathrm{O}-\mathrm{Cl}$ system at $500{ }^{\circ} \mathrm{C}$. All thermodynamic data has been obtained from HSC Chemistry 6.0.

(1), and that it would require a relatively high (negative) potential to electroplate, in the same manner as the $\mathrm{Li}^{+}$from the fused salt. From the diagram, we may also deduce that a greater concentration of $\mathrm{O}^{2-}$ ions in the eutectic melt will retard the reduction process of $\mathrm{Co}_{3} \mathrm{O}_{4}$ to $\mathrm{Co}$ metal. As the $\mathrm{O}^{2-}$ ion activity fluctuates throughout the experiment, the required reduction potential may also vary. It is therefore important that the $\mathrm{O}^{2-}$ ion concentration is kept as low as possible. With respect to the reduction of $\mathrm{CO}_{3} \mathrm{O}_{4}$, there are two steps in the formation of Co metal. These steps are outlined in Eqs. (2) and (3); Eqs. (4) and (5) represent how the standard equilibrium potential, $E$, was calculated, where $\Delta G$ is the Gibbs free energy of the reaction, $n$ is the number of moles of participating electrons, $F$ is the Faraday constant, $R$ is the universal gas constant, and $T$ is the temperature.

$3 \mathrm{LiCoO}_{2}+\mathrm{e}^{-} \rightleftharpoons 3 \mathrm{Li}^{+}+\mathrm{Co}_{3} \mathrm{O}_{4}+2 \mathrm{O}^{2-}$

$\mathrm{Co}_{3} \mathrm{O}_{4}+2 \mathrm{e}^{-} \rightleftharpoons 3 \mathrm{CoO}+\mathrm{O}^{2-}$

$\mathrm{CoO}+2 \mathrm{e}^{-} \rightleftharpoons \mathrm{Co}+\mathrm{O}^{2-}$

$E_{2}=\frac{-\Delta G_{2}}{n F}+\frac{R T \ln 10}{n F} p \mathrm{O}^{2-}$

$E_{3}=\frac{-\Delta G_{3}}{n F}+\frac{R T \ln 10}{n F} \mathrm{pO}^{2-}$

The thermodynamic analysis stipulates that the electrochemical reduction process for cobalt oxide involves two reactions, Eqs. (2) and (3), and that the $\mathrm{O}^{2-}$ ion activity level ultimately has little to no effect on the reduction procedure, as cobalt metal can be produced, with adjustment to the potential applied, at all oxide ion activity levels.

\subsection{Cyclic voltammetry}

Cyclic voltammetry measurements were recorded using a tungsten working electrode on a static setup first; the voltammogram at $450{ }^{\circ} \mathrm{C}$ is presented in Fig. 4 (a). This set-up was initially used to enable the retrieval of high signal-to-noise data showing clear reaction peaks and to understand the electrochemical system before agitation using a fluidised cathode setup. The working electrode was swept between 0 and $-2.7 \mathrm{~V}$ at a scan rate of $50 \mathrm{mV}$ 

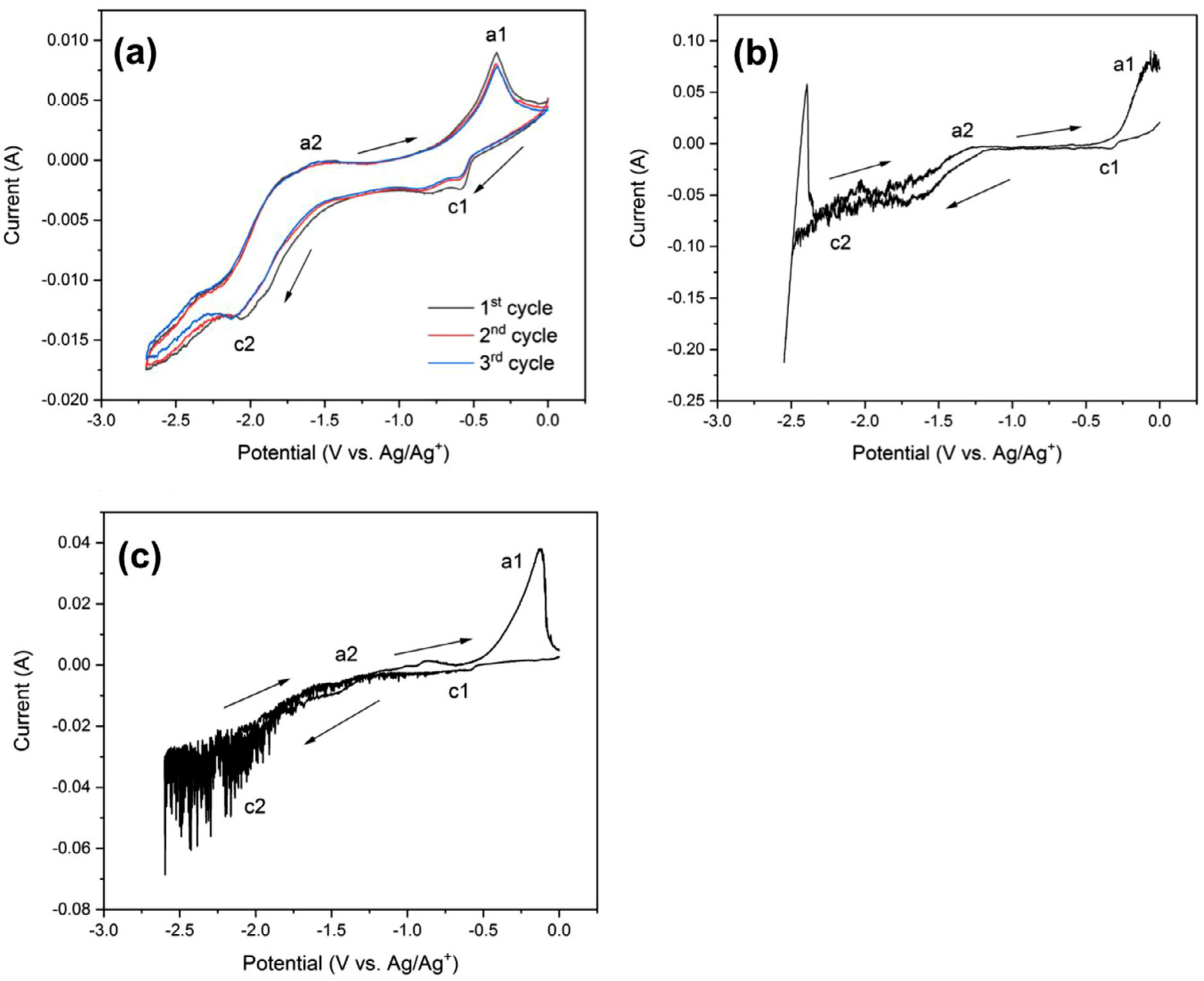

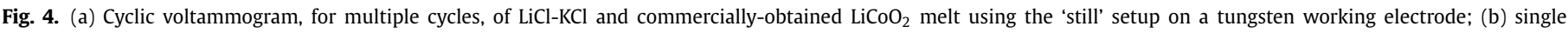

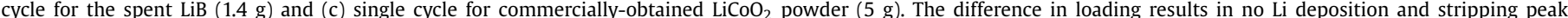

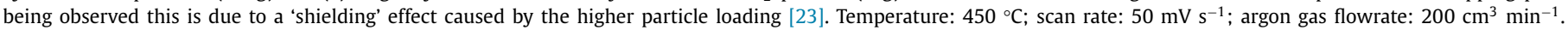

$\mathrm{S}^{-1}$ thereby avoiding the salt's decomposition potential $(\sim-2.8 \mathrm{~V})$; three potential cycles were performed. The coupled redox potentials (described in Eq. (2)) at $\mathrm{c} 1$ and a1 represent the reduction of $\mathrm{Co}_{3} \mathrm{O}_{4}$ to $\mathrm{CoO}$ and the reoxidation of $\mathrm{CoO}$ back to $\mathrm{Co}_{3} \mathrm{O}_{4}$. The second coupled redox potentials (described in Eq. (3)) at c2 and a2 represent the second reduction step where $\mathrm{CoO}$ is converted to $\mathrm{Co}$ metal and $\mathrm{Co}$ is reoxidised back to $\mathrm{CoO}$, respectively. The general form of the electrochemical response is consistent with previous results [34]; the difference in redox potentials is due to kinetic limitations as the temperatures and molten salt eutectics used in this system $\left(750{ }^{\circ} \mathrm{C}\right.$ vs. $450{ }^{\circ} \mathrm{C}$ used here) are different to others.

Next, cyclic voltammetry measurements were performed on the fluidised cathode arrangement, this is presented in Fig. 4 (b) and (c). The tungsten working electrode was scanned between 0 and $-2.55 \mathrm{~V}$ in Fig. 4 (b) and from 0 to $-2.7 \mathrm{~V}$ in Fig. 4 (c), and then back to the starting potential (vs. $\mathrm{Ag} / \mathrm{Ag}^{+}$). Again, the coupled redox potentials at $\mathrm{c} 1$ and a1 represent the reduction of $\mathrm{Co}_{3} \mathrm{O}_{4}$ to $\mathrm{CoO}$, and its reoxidation, as described in Eq. (2). The second coupled redox potentials at $\mathrm{c} 2$ and $\mathrm{a} 2$ represent the reduction of $\mathrm{CoO}$ to $\mathrm{Co}$, and its reoxidation, as described in Eq. (3). The fluidised cathode system reveals an interesting electrochemical feature, the apparent 'noise' in the cyclic voltammetry has been associated with particle/current collector reactions, as has been observed in previous studies in the fluidised cathode system [23]. These collision-reaction features (i.e. illustrated by a 'noisy' system) are present at potentials where $\mathrm{Co}_{3} \mathrm{O}_{4}$ reduction takes place and may extend into the decomposition potential of the Li salt, as shown by Fig. 4 (c). Upon observing the anodic sweep this phenomenon does not occur; therefore, the re-oxidation of Co metal to $\mathrm{Co}_{\mathrm{x}} \mathrm{O}_{\mathrm{x}}$ is primarily a surface-based process. In this system the electrochemical process proceeds from approximately -0.33 to -0.52 $\mathrm{V}$ (vs. $\mathrm{Ag} / \mathrm{Ag}^{+}$) in Fig. 4 (b) and (c), respectively.

When comparing the voltammograms of the static arrangement against the fluidised cathode setup, there is significantly more current that is passed when the reaction mixture is fluidised, where the current collector size grows as the reaction proceeds, although some spalling occurs. This is to be expected as the current is influenced by the rate of collision and reactions become more favourable and frequent, when compared to a solid precursor (pellet) or a still (quiescent) set-up.

\subsection{Constant cell voltage electrolysis}

Plotting current versus time curves provides an overview of the reduction pathway assumed in a given electrochemical process. For this study, the $\mathrm{LiCoO}_{2}$ cathode material was subjected to a fixed potential of $-2.4 \mathrm{~V}$ ( $\mathrm{vs}$. $\mathrm{Ag} / \mathrm{Ag}^{+}$). This potential was chosen using the data acquired from Fig. 4, and a value of $-2.4 \mathrm{~V}$, represented the most likely reduction potential to $\mathrm{LiCoO}_{2}$. The reduction potential is more positive than the expected decomposition potential of the salt and should therefore avoid Li electroplating. As observed from Fig. 5 (a) and (d), the current increased, quickly approaching 

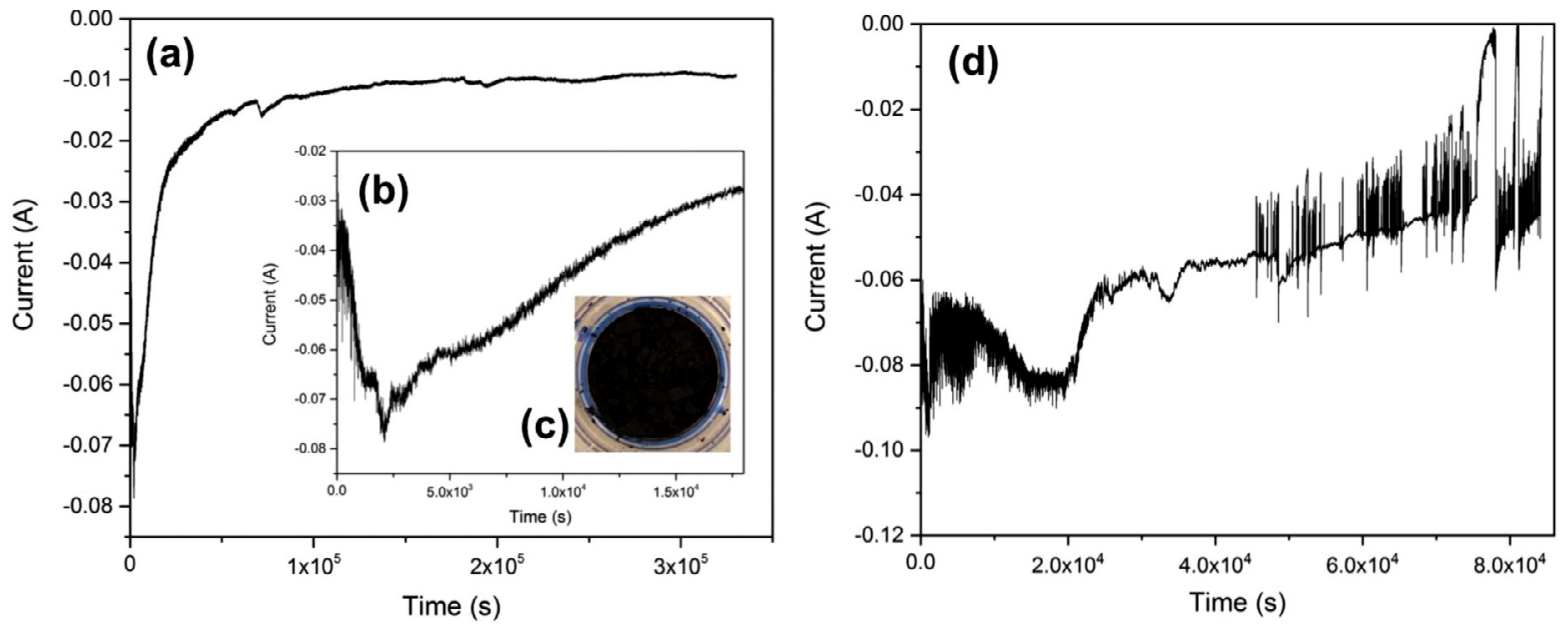

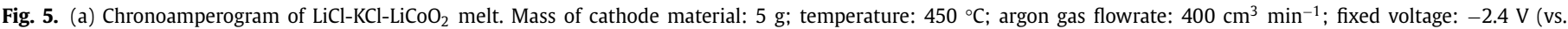

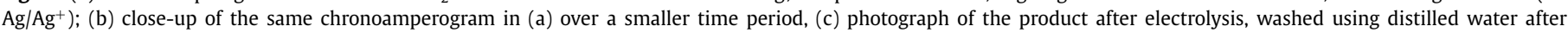

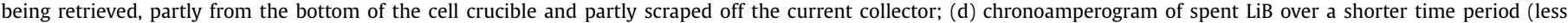
than $24 \mathrm{~h}$ ) using identical conditions to (a), the completion of the process was denoted by the sudden drop in current.

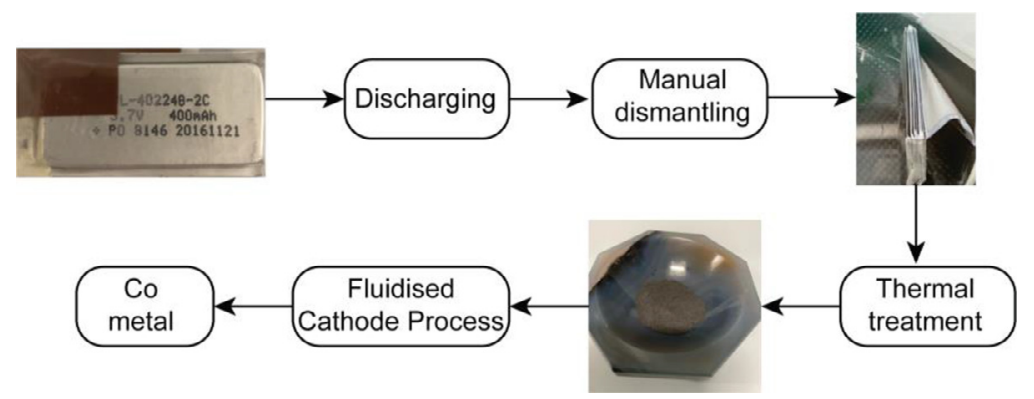

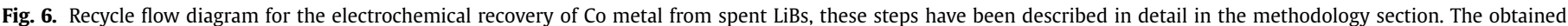
Co metal at the completion is expected to be used in several LiB applications but also in the formation of alloys.

nearly $80 \mathrm{~mA}$ in Fig. 5 (a) and $90 \mathrm{~mA}$ in Fig. 5 (d) due to the deposit growth of Co metal on the substrate electrode surface. One explanation for the current increase, which has been evidenced in previous work [22], is that it could arise due to the difference in particle size distribution which means some particles undergo partial reduction. This enables a higher probability of contact between the metal oxide and salt and improves the reduction rate. Fig. 5 (c) shows a photograph of the product after it was washed with distilled water compared with the starting material photographed in Fig. 6. The final product appeared to be a homogeneous grey-black powder, indicative of cobalt metal, and both SEM/EDS analyses, in Fig. 7 (a)-(c), and the EDS spectrum in the Supplementary Material, indicated that oxygen was absent in the final Co product. At higher magnifications, Fig. 7 (a) and (b), the Co metal particles produced appear homogeneous in size and porosity, depicting a 'corallike' structure, which indicate a feature size of $2-3 \mu \mathrm{m}$. The same is true of Fig. 7 (c) although there is also some presence of cobalt silicate particles which are assumed to be due to the reaction of borosilicate glass with the cobalt ions in the molten salt system.

The current versus time curves for both studies can be separated into two segments. The first segment is associated with a rapid rate of reduction and is observed in Fig. 5 (b) and (d) where the current rises. This rise in current is a result of the increasing electrode surface area. The second segment is where the current begins to fall. Fig. 5 (d) is where the periodic spalling is most noticeable and is denoted by a rapid loss of current for short periods towards the end of the process. The depletion of available oxide from the reaction is realised once the current reaches the background level or zero. From calculations, $1640 \mathrm{C}$ has been deter- mined as the total theoretical charge that would be required to reduce the $\mathrm{LiCoO}_{2}(5 \mathrm{~g})$, assuming $100 \%$ current efficiency. Acknowledging incomplete reduction and extrapolating towards the background current, resulted in a current efficiency between $70 \%$ and $80 \%$ in Fig. 5 (a) and was upwards of $80 \%$ in Fig. 5 (d) [22].

\section{Conclusions}

This work demonstrates that the recovery of Co metal is feasible using the fluidised cathode technique from commerciallyobtained and spent $\mathrm{LiCoO}_{2}$ cathode material. It serves as an important step for the electroreduction of metal oxides to their elemental state. The results from the chronoamperometry reveal that the fluidised cathode process possesses a high Faradaic efficiency of $>70 \%$. By using this process, several steps in the flowsheet presented in Fig. 1 can therefore be eliminated; namely the leaching and regeneration steps. It also utilises a molten salt eutectic ( $\mathrm{LiCl}-$ $\mathrm{KCl})$ at a much lower temperature $\left(450{ }^{\circ} \mathrm{C}\right.$ ) leading to considerable cost reductions overall. The decision to forgo the regeneration step was made on the fact that the market share of $\mathrm{LiCoO}_{2}$ cathode material is falling; therefore, producing high-quality pure-phase Co metal is practical for other uses which include the formation of lithiated cobalt-oxides in LiBs (e.g. NMC and NCA). Given the success of this work, the authors envision this technology to be applied to the aforementioned battery electrode materials, with the possibility of selectively reducing and separating different materials, other components of a battery and other types of batteries. 

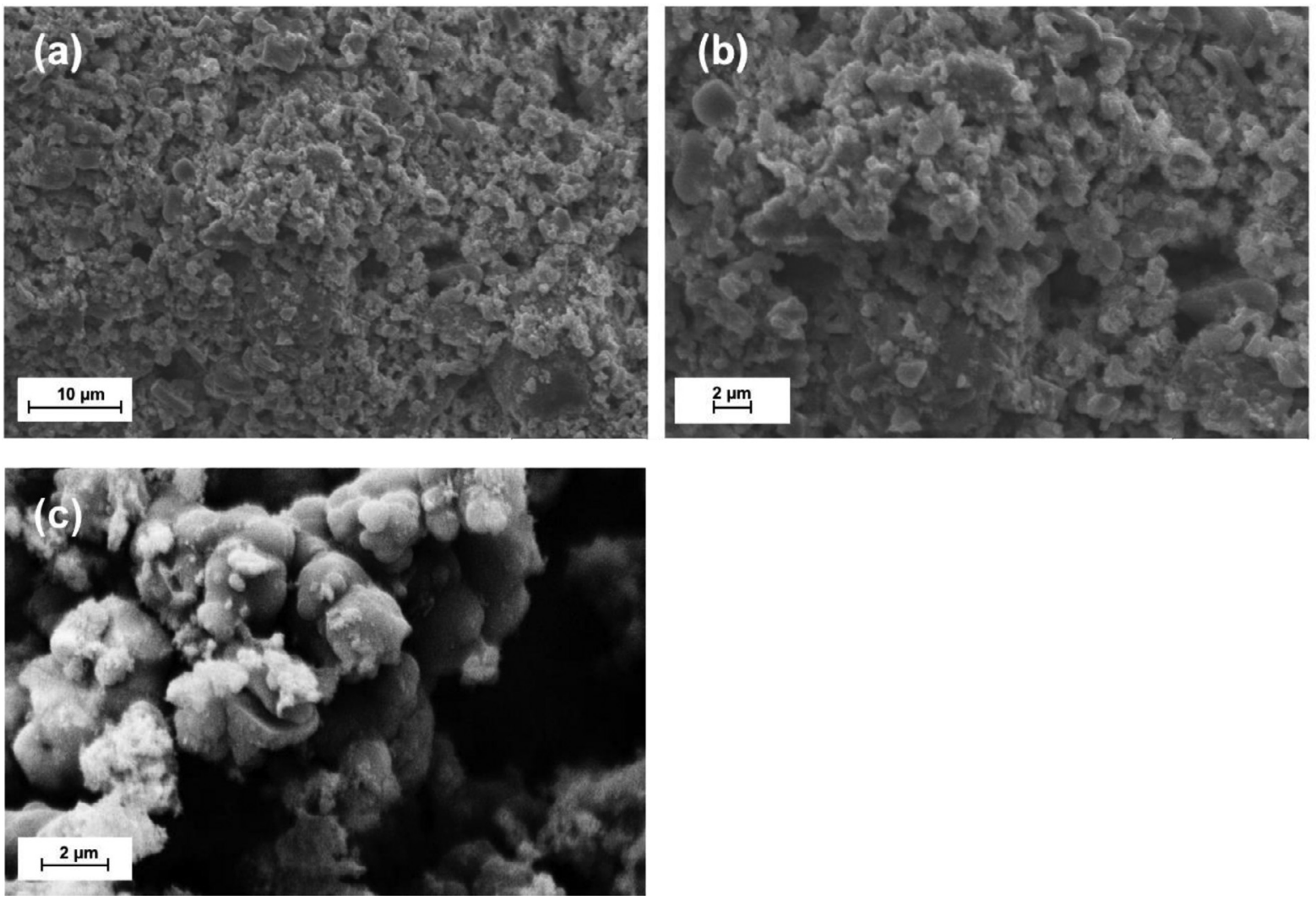

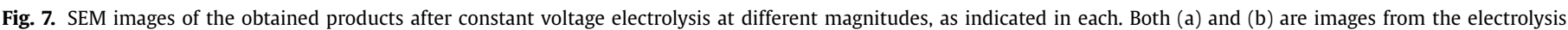

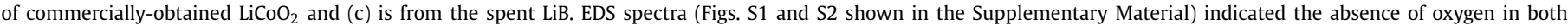
cases.

\section{Declaration of Competing Interest}

The authors declare that they have no known competing financial interests or personal relationships that could have appeared to influence the work reported in this paper.

\section{Credit authorship contribution statement}

Mateen Mirza: Investigation, Formal analysis. Rema Abdulaziz: Investigation, Formal analysis. William C. Maskell: Supervision, Formal analysis. Chun Tan: Investigation, Formal analysis. Paul R. Shearing: Funding acquisition, Formal analysis. Dan J.L. Brett: Conceptualization, Funding acquisition, Supervision, Formal analysis.

\section{Acknowledgement}

This work was supported by the STFC Network in Batteries and Electrochemical Devices (ST/R006873/1). Shearing acknowledges financial support from the Royal Academy of Engineering (CiET1718/59). The authors also acknowledge support from the EPSRC (EP/R023581/1).

\section{Supplementary materials}

Supplementary material associated with this article can be found, in the online version, at doi:10.1016/j.electacta.2021.138846.

\section{Reference}

[1] L. Li, E. Fan, Y. Guan, X. Zhang, Q. Xue, L. Wei, F. Wu, R. Chen, Sustainable Recovery of Cathode Materials from Spent Lithium-Ion Batteries Using Lactic Acid Leaching System, ACS Sustain. Chem. Eng. 5 (2017) 5224-5233.
[2] Y. Xu, Y. Dong, X. Han, X. Wang, Y. Wang, L. Jiao, H. Yuan, Application for Simply Recovered $\mathrm{LiCoO}_{2}$ Material as a High-Performance Candidate for Supercapacitor in Aqueous System, ACS Sustain. Chem. Eng. 3 (2015) 2435-2442.

[3] J.B. Goodenough, Y. Kim, Challenges for rechargeable batteries, J. Power Sources 196 (2011) 6688-6694.

[4] K. Zaghib, M. Dontigny, A. Guerfi, P. Charest, I. Rodrigues, A. Mauger C.M. Julien, Safe and fast-charging Li-ion battery with long shelf life for power applications, J. Power Sources 196 (2011) 3949-3954.

[5] M. Berecibar, I. Gandiaga, I. Villarreal, N. Omar, J. Van Mierlo, P. Van den Bossche, Critical review of state of health estimation methods of Li-ion batteries for real application, Renew. Sust. Energ. Rev. 56 (2016) 572-587.

[6] D. Justus, International Energy Agency (IEA), Global EV Outlook 2018 Towards cross modal electrification, 2018 Technology Report, Paris.

[7] G.M. Mudd, Z. Weng, S.M. Jowitt, I. Turnbull, T. Graedel, Quantifying the recoverable resources of by-product metals: The case of cobalt, Ore Geol. Rev. 55 (2013) 87-98.

[8] S.H. Mohr, G.M. Mudd, D. Giurco, Lithium Resources and Production: Critical Assessment and Global Projections, Minerals 2 (2012) 65-84.

[9] S.A. El-Safty, M.R. Awual, M. Shenashen, A. Shahat, Simultaneous optical detection and extraction of cobalt(II) from lithium ion batteries using nanocollector monoliths, Sensor. Actuat. B-Chem. 176 (2013) 1015-1025.

[10] J.F. Peters, M. Baumann, B. Zimmermann, J. Braun, M. Weil, The environmental impact of Li-Ion batteries and the role of key parameters - A review, Renew Sustain. Energ. Rev. 67 (2017) 491-506

[11] J.B. Dunn, L. Gaines, J. Sullivan, M.Q. Wang, Impact of Recycling on Cradle-toGate Energy Consumption and Greenhouse Gas Emissions of Automotive Lithium-Ion Batteries, Environ. Sci. Technol. 46 (2012) 12704-12710.

[12] G. Harper, R. Sommerville, E. Kendrick, L. Driscoll, P. Slater, R. Stolkin, A. Walton, P. Christensen, O. Heidrich, S. Lambert, Recycling lithium-ion batteries from electric vehicles, Nature 575 (2019) 75-86.

[13] O. Velázquez-Martínez, J. Valio, A. Santasalo-Aarnio, M. Reuter, R. Serna-Guerrero, A Critical Review of Lithium-Ion Battery Recycling Processes from a Circular Economy Perspective, Batteries 5 (2019) 68

[14] H. Zou, E. Gratz, D. Apelian, Y. Wang, A novel method to recycle mixed cathode materials for lithium ion batteries, Green Chem 15 (2013) 1183-1191.

[15] J. Hu, J. Zhang, H. Li, Y. Chen, C. Wang, A promising approach for the recovery of high value-added metals from spent lithium-ion batteries, J. Power Sources 351 (2017) 192-199.

[16] B. Swain, J. Jeong, J-C. Lee, J-H. Lee, J-S. Sohn, Hydrometallurgical process for recovery of cobalt from waste cathodic active material generated during manufacturing of lithium ion batteries, J. Power Sources 167 (2007) 536-544. 
[17] L. Sun, K. Qiu, Vacuum pyrolysis and hydrometallurgical process for the recovery of valuable metals from spent lithium-ion batteries, J. Hazard. Mater. 194 (2011) 378-384.

[18] G.Z. Chen, D.J. Fray, T.W. Farthing, Direct electrochemical reduction of titanium dioxide to titanium in molten calcium chloride, Nature 407 (2000) 361-364.

[19] D. Alexander, C. Schwandt, D. Fray, Microstructural kinetics of phase transformations during electrochemical reduction of titanium dioxide in molten calcium chloride, Acta Mater 54 (2006) 2933-2944.

[20] K. Dring, R. Bhagat, M. Jackson, R. Dashwood, D. Inman, Direct electrochemical production of Ti-10W alloys from mixed oxide preform precursors, J. Alloys Compd. 419 (2006) 103-109.

[21] R. Bhagat, D. Dye, S.L. Raghunathan, R.J. Talling, D. Inman, B.K. Jackson, K. Rao, R.J. Dashwood, In situ synchrotron diffraction of the electrochemical reduction pathway of $\mathrm{TiO}_{2}$, Acta Mater 58 (2010) 5057-5062.

[22] R. Abdulaziz, L. Brown, D. Inman, C.A. Sharrad, A. Jones, P.R. Shearing, D.J.L. Brett, Electrochemical Reduction of $\mathrm{UO}_{2}$ to $\mathrm{U}$ in LiCl-KCl Molten Salt Eutectic Using the Fluidized Cathode Process, J. Electrochem. Soc. 164 (2017) H5280-H5285.

[23] R. Abdulaziz, L.D. Brown, D. Inman, P.R. Shearing, D.J.L. Brett, Electrochemical Reduction of Tungsten Oxide in LiCl-KCl Molten Salt Eutectic using the Fluidised Cathode Process, Electrochim. Acta 226 (2017) 18-28.

[24] R. Abdulaziz, L.D. Brown, D. Inman, S. Simons, P.R. Shearing, D.J.L Brett, Novel fluidised cathode approach for the electrochemical reduction of tungsten oxide in molten LiCl-KCl eutectic, Electrochem. Commun. 41 (2014) 44-46.

[25] L.D. Brown, R. Abdulaziz, R. Jervis, V.J. Bharath, R.C. Atwood, C. Reinhard, L.D. Connor, S.J.R. Simons, D. Inman, D.J.L. Brett, P.R. Shearing, Following the electroreduction of uranium dioxide to uranium in $\mathrm{LiCl}-\mathrm{KCl}$ eutectic in situ using synchrotron radiation, J. Nucl. Mater. 464 (2015) 256-262.

[26] A.R. Kamali, D. Fray, Electrochemical interaction between graphite and molten salts to produce nanotubes, nanoparticles, graphene and nanodiamonds, J. Mater. Sci. 51 (2016) 569-576.

[27] A.R. Kamali, D.J. Fray, Towards large scale preparation of carbon nanostructures in molten LiCl, Carbon 77 (2014) 835-845.

[28] A. Rezaei, A.R. Kamali, Green production of carbon nanomaterials in molten salts, mechanisms and applications, Diam. Relat. Mater. 83 (2018) 146-161.

[29] H. Kim, D.A. Boysen, J.M. Newhouse, B.L. Spatocco, B. Chung, P.J. Burke, D.J. Bradwell, K. Jiang, A.A. Tomaszowska, K. Wang, Liquid Metal Batteries: Past, Present, and Future, Chem. Rev. 113 (2013) 2075-2099.

[30] H. Yin, B. Chung, F. Chen, T. Ouchi, J. Zhao, N. Tanaka, D.R. Sadoway, Faradaically selective membrane for liquid metal displacement batteries, Nat. Energy 3 (2018) 127-131.

[31] K. Wang, K. Jiang, B. Chung, T. Ouchi, P.J. Burke, D.A. Boysen, D.J. Bradwell, H. Kim, U. Muecke, D.R. Sadoway, Lithium-antimony-lead liquid metal battery for grid-level energy storage, Nature 514 (2014) 348-350.

[32] B. Cui, S. Licht, A low temperature iron molten air battery, J. Mater. Chem. A 2 (2014) 10577-10580.

[33] X. Qu, H. Xie, X. Chen, Y. Tang, B. Zhang, P. Xing, H. Yin, Recovery of $\mathrm{LiCoO}_{2}$ from Spent Lithium-Ion Batteries through a Low-Temperature Ammonium Chloride Roasting Approach: Thermodynamics and Reaction Mechanisms, ACS Sustain. Chem. Eng. 8 (2020) 6524-6532.
[34] B. Zhang, H. Xie, B. Lu, X. Chen, P. Xing, J. Qu, Q. Song, H. Yin, A Green Electrochemical Process to Recover $\mathrm{Co}$ and $\mathrm{Li}$ from Spent $\mathrm{LiCoO}_{2}$-Based Batteries in Molten Salts, ACS Sustain. Chem. Eng. 7 (2019) 13391-13399.

[35] S. Zhou, Y. Zhang, Q. Meng, P. Dong, X. Yang, P. Liu, Q. Li, Z. Fei, Recycling of spent $\mathrm{LiCoO}_{2}$ materials by electrolytic leaching of cathode electrode plate, J. Environ. Chem. Eng. 9 (2021) 104789.

[36] S. Zhou, Y. Zhang, Q. Meng, P. Dong, Z. Fei, Q. Li, Recycling of $\mathrm{LiCoO}_{2}$ cathode material from spent lithium ion batteries by ultrasonic enhanced leaching and one-step regeneration, J. Environ. Manage. 277 (2021) 111426.

[37] Y. Zhang, Q. Meng, P. Dong, J. Duan, Y. Lin, Use of grape seed as reductant for leaching of cobalt from spent lithium-ion batteries, J. Ind. Eng. Chem. 66 (2018) 86-93.

[38] Q. Meng, Y. Zhang, P. Dong, Use of glucose as reductant to recover Co from spent lithium ions batteries, Waste Manag 64 (2017) 214-218.

[39] Q. Meng, Y. Zhang, P. Dong, F. Liang, A novel process for leaching of metals from $\mathrm{LiNi}_{1 / 3} \mathrm{Co}_{1 / 3} \mathrm{Mn}_{1 / 3} \mathrm{O}_{2}$ material of spent lithium ion batteries: Process optimization and kinetics aspects, J. Ind. Eng. Chem. 61 (2018) 133-141.

[40] Q. Meng, Y. Zhang, P. Dong, A combined process for cobalt recovering and cathode material regeneration from spent $\mathrm{LiCoO}_{2}$ batteries: Process optimization and kinetics aspects, Waste Manag 71 (2018) 372-380.

[41] Q. Meng, Y. Zhang, P. Dong, Use of electrochemical cathode-reduction method for leaching of cobalt from spent lithium-ion batteries, J. Clean. Prod. 180 (2018) 64-70.

[42] G. Jiang, Zhang Y, O. Meng, Y. Zhang, P. Dong, M. Zhang, X. Yang, Direct Regeneration of $\mathrm{LiNi}_{0.5} \mathrm{Co}_{0.2} \mathrm{Mn}_{0.3} \mathrm{O}_{2}$ Cathode from Spent Lithium-Ion Batteries by the Molten Salts Method, ACS Sustain. Chem. Eng. 8 (2020) 18138-18147.

[43] S.K. Cho, F.F. Fan, A.J. Bard, Formation of a silicon layer by electroreduction of $\mathrm{SiO}_{2}$ nanoparticles in $\mathrm{CaCl}_{2}$ molten salt, Electrochim. Acta 65 (2012) 57-63.

[44] K. Xie, A.R. Kamali, Molten salt electrochemical production and in situ utilization of hydrogen for iron production, Int. J. Hydrog. Energy 44 (2019) 24353-24359.

[45] Y. Deng, D. Wang, W. Xiao, X. Jin, X. Hu, G.Z. Chen, Electrochemistry at Conductor/Insulator/Electrolyte Three-Phase Interlines: A Thin Layer Model, J. Phys. Chem. B 109 (2005) 14043-14051.

[46] J.O.M. Bockris, G.J. Hills, D. Inman, L. Young, An all-glass reference electrode for molten salt systems, J. Sci. Inst. 33 (1956) 438-439.

[47] R. Littlewood, Diagrammatic Representation of the Thermodynamics of MetalFused Chloride Systems, J. Electrochem. Soc. 109 (1962) 525

[48] K. Dring, R. Dashwood, D. Inman, Predominance Diagrams for Electrochemical Reduction of Titanium Oxides in Molten $\mathrm{CaCl}_{2}$, J, Electrochem. Soc. 152 (2005) D184.

[49] R. Abdulaziz, L.D. Brown, D. Inman, S. Simons, P.R. Shearing, D.J.L. Brett, Predominance Diagrams of Spent Nuclear Fuel Materials in LiCl-KCl and $\mathrm{NaCl}-\mathrm{KCl}$ Molten Salt Eutectics, Int. J. Electrochem. Sci. 11 (2016) 10417-10435.

[50] L.D. Brown, R. Abdulaziz, S. Simons, D. Inman, D.J.L. Brett, P.R. Shearing, Predominance diagrams of uranium and plutonium species in both lithium chloride-potassium chloride eutectic and calcium chloride, J. Appl. Electrochem. 43 (2013) 1235-1241 